\title{
Research on the Construction of University Curriculum Map Supported by Big Data
}

\author{
Fan Yang, Yue Wang \\ College of Humanities \& Sciences \\ Northeast Normal University \\ Changchun, China
}

\begin{abstract}
Curriculum map is an important basis for student planning, teacher review courses, and school planning courses. It has been widely adopted in Europe, America and Taiwan, China. With the development of big data technology, the connotation of curriculum maps is constantly enriched. With the support of big data, fully explore the connection between data, it select recommendations through accurate courses, deepen the diagnosis of course conflicts, strengthen the feedback of course results, draw a map of college courses, improve students' interest in learning, save the teaching staff, optimize teaching work and has opened up another direction for the application of big data in education. With the support of big data, the curriculum map will develop in the direction of individualization, relevance, interaction and intelligence.
\end{abstract}

Keywords-Big Data; Curriculum Map; Personalization; Interactive

\section{INTRODUCTION}

In recent years, with the comprehensive coverage of the Internet on campus, the network has become more and more integrated into the daily learning lives of students. Along with the fact that a large amount of data is continuously recorded and accumulated, the speed is fast, the volume is large and unprecedented. How to integrate these large-volume and diverse data into daily teaching management, curriculum selection, curriculum learning and assessment, and evaluation, so that these data generate value and be applied, worthy of deep thinking and discussion. curriculum maps are widely used in Europe, the United States and Taiwan, China [1], and curriculum maps are used to improve student learning, teach teachers, and improve school management. Numerous studies have shown that schools that have participated in the development of curriculum maps believe that this initiative is successful [2], and the curriculum map helps them to carry out student academic planning, teacher curriculum integration and school curriculum construction. Drawing on the successful experience of curriculum map construction in foreign countries and Taiwan Province of China, it provides relevant enlightenment and suggestions for the construction of curriculum maps supported by big data in China.

\section{FocUSING ON THE TREND OF BIG DATA ANALYSIS CURRICULUM MAP CONSTRUCTION}

Curriculum maps originate from the use of surveys and interviews by third-party personnel, collecting data and feeding back to schools and teachers to promote teaching activities in

Fund Project: Social Science Project of the "13th Five-Year Plan" of Education Department in Jilin Province, "Research on Aggregation of Learning Resources based on Visualization from the Perspective of Big Data" (Project No. JJKH20190359SK) line with teaching plans. [3] The calendar is then used as an organization form of the curriculum map. Teachers are required to fill in the description of the professor's content according to the time period, and generate a "map" that describes the course, contains the content and skills, and evaluates the students. [4] The curriculum map is a road sign-like tool that provides guidance to students, teachers, academic staff, and other relevant personnel by presenting the course elements and their connections. A typical curriculum map is a relational database. If education is seen as a journey, teachers should use some resources to provide guidance to students, and curriculum maps are such a tool. [5]

Since the curriculum map involves all aspects of teaching and the amount of information is large, it is usually time-consuming and labor-intensive to construct a traditional paper curriculum map. In recent years, the rapid development of the Internet has solved this problem well. The Birmingham School of Medicine in the United Kingdom developed an e-curriculum map using the Filmmaker Pro database and sent it to the school's teachers and students via the Internet. The Curriculum Mapper is the world's first curriculum map commercial software and the world's largest course database. CurrMIT is a curriculum map database developed by the American Medical Association to collect course information from most medical schools in the United States and Canada. [6] Researchers at Datong University in Taiwan proposed the use of knowledge engineering methodology and semantic web technology to develop intelligent curriculum maps, provide students with academic and career development diagnostic advice, provide a basis for school curriculum design, and a reference for recruiting talents. [7] In China, there are not much application of curriculum maps in colleges and universities. Literature research found that Beijing University of Chemical Technology, Capital Normal University, Ningbo University Science and Technology College and other universities are using this concept to develop relevant systems.

The development of big data technology makes the data-based curriculum map more precise and humanized, which satisfies the students' autonomy of course selection, enhances students' interest in learning, saves the teaching staff, optimizes the teaching work, and has opened up another direction for the application of big data in education. Although big data is only emerging in the current curriculum development, in terms of long-term development, the extraordinary ability of data acquisition, storage, management and analysis of big data has undoubtedly injected a powerful 
impetus to optimize curriculum maps. In this sense, focusing on big data indicates the new direction of curriculum map construction.

\section{THE VALUE OF THE ALLIANCE MAP DATA EXPLORATION COURSE CONSTRUCTION}

Big data is an insight into and predicting trends in things like never before. It has become an important issue in the field of educational informationization to enable the massive amount of data that is submerged in many information systems to "speak". The value of curriculum map construction is more prominent with the support of big data.

\section{A. Big data precision course selection recommendation, to achieve personalized learning}

With the deepening reform and development of higher education, in order to give full play to the advantages of teaching resources in colleges and universities, combined with the differences between students' courses and majors, the course selection system is adopted. This not only respects the individualized learning needs of students but also more scientifically matches the teaching resources of colleges and universities. The elective system is more conducive to expanding the knowledge of students and better integrating the teaching resources of higher education. However, students have a certain degree of blindness and spontaneity in the course of course selection and need effective guidance. Big data can accurately recommend courses that meet the characteristics and preferences of students. In the era of big data, it is better to make better use of the teaching resources of colleges and universities. The positive and important meaning

\section{B. Big data deepens course conflict diagnosis and optimizes the curriculum system}

The main functions of the curriculum map can be reflected in improving the quality of the course system, promoting teacher teamwork, meeting the needs of different users, and promoting the effective integration of learning resources. For example, Hege et al. found through the curriculum map that eight target items in the occupational medicine and environmental medicine programs at the University of Munich School of Medicine in Germany were not reflected in the specific courses and teaching; the content between some courses was too much; learning The goal appears in the relevant exam, but it is not included in any of the taught courses. These problems are also common in Chinese universities, and curriculum maps are effective tools for discovering and eliminating such problems and improving the quality of the curriculum system. [8] Big data can more quickly discover conflicts in these courses and effectively solve these problems in the curriculum map.

\section{Big data strengthens the feedback of the course results and enhances the learning effect}

For the individual students, according to the big data of the students' learning situation, the students get the weak knowledge points, and according to the links between the courses in the curriculum map, find out the relevant missing courses and give feedback to the students themselves, so as to be targeted. Tutoring and tutoring. For the student group, if there is a learning problem of the same knowledge point that most students have, feedback to the teacher prompts the teacher to adjust the revised teaching content or improve and improve the teaching method.

\section{LEVERAGE THE DIRECTION OF BIG DATA DEVELOPMENT CURRICULUM MAP CONSTRUCTION}

The development of big data has ushered in new opportunities for the development of curriculum maps. Through big data, you can understand the status of student learning, the status of the course, the status of the course system, and so on. The curriculum map will develop in the future in the direction of individualization, relevance, interaction and intelligence.

\section{A. Personalization}

An important part of the application of big data in the field of higher education is to carry out personalized education for students, teach students in accordance with their aptitude, and recommend courses that are of interest to college students and are more helpful for future studies and employment. By applying the system recommendation of big data technology, the system can understand the needs of students more directly and accurately, and after constructing the corresponding recommendation model for analysis, students can learn what courses other students are choosing and get reasonable suggestions when selecting courses. Students are no longer confused when they choose courses, so that the course selection is in line with their own development and more humane.

\section{B. Relevance}

The reason why the curriculum map is not the curriculum is that there are many "roads" connected in the "map", and the nodes in the curriculum map are related to each other. The curriculum map is not a simple course stacking, but a lively course path to help students navigate the ocean of knowledge. On the basis of the general plan of the course, set the relationship diagram between the curriculum and the ability, show the relationship between the course learning and the acquisition of core competence; the course content relationship diagram, show the mutual connection between different courses, share knowledge points, etc.; curriculum and professional Directional relationship diagram, showing the relationship between the curriculum needs of different subjects in the same profession and the curriculum; the relationship between curriculum and development, showing the relationship between the completion of important courses in the professional category and the future work. The establishment of several kinds of relationship maps clarified the various relationships between the courses so that the students have a more rational understanding of the courses they have studied and improved the motivation of the course.

\section{Interactivity}

Curriculum map construction is an effective tool to promote interaction between students and teachers, teachers and school administrators, school administrators and assessment experts. The design of the curriculum system reflects the ideas, concepts and purposes of the educators, and the construction of the curriculum map is the intermediary that turns the theory into practice. Through the curriculum map, 
students can discover the basic courses that were lacking in the current learning bottleneck of a certain course, and then ask the teacher for advice in a targeted manner. They can also directly ask the teachers of the relevant courses. Teachers can also study the learning rules of students according to the curriculum map, solve the problems encountered by students from the root, and achieve the purpose of good interaction and teaching. Through the improvement of teaching, teachers work with school administrators to improve the curriculum and curriculum system. Through the curriculum map website, the evaluation experts can use the online review method to understand whether the professional goals and learning results are consistent with the actual school, whether the curriculum system and course content meet the requirements of the learning outcomes, whether the academic evaluation methods and methods, and the test papers are related to the learning outcomes. Whether the arrangement between the course and the experiment is reasonable, as well as the details and key criteria that needs to be evaluated, etc.

\section{Intelligent}

The curriculum map is a dynamic process, clearly depicting the curriculum structure, course requirements and sequence, as a guide for students' elective courses, to help students understand the course content of the course selection, and to choose the most suitable interests and professional choices from many courses. Your own course of choice provides students with complete learning and application. However, current university curriculum maps only provide linear browsing and keyword search services, and the query in the learning path (course) does not accommodate all possibilities to meet individual needs. Therefore, based on big data analysis to develop intelligent curriculum maps, provide student learning and personal development diagnostic consultation, provide teachers with improved curriculum and teaching foundation, and provide the basis for school curriculum design.

\section{CONCLUSION}

This article starts with the development of curriculum map, from the early use of third-party personnel to record classrooms, to the use of school calendars by teachers as an organizational form; from the use of maps to represent the relationship between courses, to the use of relational databases to reflect development trends. The wide application of big data provides a new development direction for curriculum map construction

Big data is an unprecedented way to perceive and predict the development of things, and thus profoundly affect people's cognitive style, value judgment and behavior choice. As a tool to guide the learning process, we explore the value of curriculum map construction from the three core elements of big data improvement learning process: individualization, probability prediction and feedback.

With the development of big data, the curriculum map welcomes new development opportunities. Big data shows not the causal relationship in the small data era, but the correlation between a series of data. The big data can be used to understand the state of student learning, the state of the course, the state of the course system, etc. In the future, students can rely on the curriculum map as a tool for learning guidance and learning assessment; teachers can rely on the curriculum map to understand the problems in the curriculum and the status of the curriculum; managers can rely on the curriculum map analysis to judge the curriculum plan and curriculum integration; The curriculum system and teaching are evaluated based on the course map. The curriculum map will develop in the future in the direction of individualization, relevance, interaction and intelligence.

\section{ACKNOWLEDGMENT}

This research was supported by Social Science Project of the "13th Five-Year Plan" of Education Department in Jilin Province, "Research on Aggregation of Learning Resources based on Visualization from the Perspective of Big Data" (Project No. JJKH20190359SK)

\section{REFERENCES}

[1] Wang Jingjing, Xia Dehong. "Exploration of University Curriculum Map Construction-Based on the Analysis of University Experience in Taiwan”, Higher Education of Science, 2015(2).(In Chinese)

[2] Ke Xiaoling. “Analysis of Curriculum Maps in Foreign Universities”, "Exploration of Higher Education”, 2012 (1). (In Chinese)

[3] Hou Zhuang, Lin Qing. "New Path of Digital Resources Integration of University Libraries Based on Curriculum Map", Modern Intelligence, 2016 (5). (In Chinese)

[4] Curriculum Mapping Overview: http://curriculumdecisions.com/curriculum-mapping/overview, 2017-08-10.

[5] Gong Jianwen, Xiao Yulei. "The Development and Enlightenment of Taiwan University Curriculum Maps on Mainland Curriculum Maps”, China Higher Education Research, 2014 (5). (In Chinese)

[6] J. Kerslake \& J. McKendree. Electronic career mapping: What are they and why would we want https://www.heacademy.ac.uk/system/files/85_cur__map_report.pdf, 2017-09-15.

[7] Ye Qinglong, Cai Huizhen. "Development of Curriculum Map Knowledge System: Conceptual Model and Knowledge Engineering”, Science and Engineering Education Journal, 2014, 47(1). (In Chinese)

[8] Hege I, Nowak D, Kolb S, et al. "Developing and analyzing a curriculum map in Occupational and Environmental Medicine”, BMC medical education, 2010, 10(01). 